\title{
Aragón Open Data y los archivos, bibliotecas y museos: nuevas posibilidades a través de datos abiertos
}

Julián Moyano Collado | Servicio de Nuevas Tecnologías y Sociedad de la Información, Dirección General de Administración Electrónica y Sociedad de la Información, Gobierno de Aragón

URL de la contribución <www.iaph.es/revistaph/index.php/revistaph/article/view/3958>

Aragón Open Data es el portal de datos abiertos del Gobierno de Aragón. Desde el 2013 se ofrecen datos y otros elementos a cualquier interesado, llegando en la actualidad a disponer de más de 2700 datasets.

Aragón Open Data ha tenido un crecimiento exponencial desde su creación, impulsado por la unidad responsable de su gestión y, cómo no, por los diferentes proveedores de datos: unidades públicas en su mayoría del gobierno autonómico y también alguna organización privada. Estos proveedores han hecho posible que sus datos se ofrezcan bajo la filosofía de los datos abiertos en un único punto de acceso.

Desde la creación del portal se han desarrollado más servicios, como por ejemplo la Aragopedia, Presupuestos de Aragón u Open Social Data; todos ellos giran en torno a la reutilización de los datos abiertos.

Por otra parte, Aragón Open Data ofrece diversas aplicaciones de uso y explotación de sus medios, junto con materiales de formación, sin olvidar que se promueven aplicaciones y servicios que permiten aprovechar mejor sus elementos con utilidades que dan valor añadido a los propios datos.

En este amplio y diverso marco, Aragón Open Data cuenta con un espacio para ofrecer datos relacionados con los archivos, bibliotecas y museos de Aragón. La incorporación de los recursos de estas instituciones se produce desde diferentes vías, entre las que destacan:

$>$ A través de la incorporación de un fichero de datos al banco de datos de Aragón Open Data. Este fichero se incorpora por su personal responsable y requiere la actualización o mantenimiento periódico para que los datos sean acordes y correctos. Por ejemplo, Archivos participantes en DARA (documentos y archivos de Aragón).

> Incorporación de una URL o dirección pública donde se accede a determinados datos relacionados con archivos, bibliotecas y museos. Esta opción remite a la fuente de datos mantenida directamente por unidades concretas. Algunos ejemplos: datos sobre superficies de bibliotecas o museos de Aragón.

> GA_OD_CORE, Gobierno de Aragón Open Data Core, aplicación que permite a desarrolladores la consulta de datos para ser usados en sus aplicaciones o desarrollos. Vista 145, DARA Archivos de Aragón.

> Punto de acceso SPARQL para extraer y explotar los diferentes recursos que se han incorporado cumpliendo los estándares de la web semántica. Por ejemplo datos relacionados con la Aragopedia.

Estos son algunos de los ejemplos de cómo se integran y sirven los datos procedentes de archivos, bibliotecas y museos a Aragón Open Data. Y aunque el camino hasta que los datos se abran y se incorporen al portal puede ser largo, proveedores proactivos como la Dirección General de Cultura y Patrimonio del Gobierno de Aragón o el Instituto Aragonés de Estadística (IAEST), que disponen de datos e información relacionada con archivos, bibliotecas y museos, facilitan y hacen posible su disponibilidad.

La incorporación de estas instituciones relacionadas con el patrimonio cultural, bibliográfico y documental a Aragón Open Data parte de la naturaleza de las propias entidades gestoras y su idiosincrasia, desde sus oríge- 
nes tienen entre sus objetivos la difusión de sus contenidos y colecciones. El marco normativo actual además promueve que participen en estas iniciativas para que sus datos y recursos sumen, aporten y se reutilicen. Incluso la Ley 18/2015, de 9 de julio, por la que se modifica la Ley $37 / 2007$, de 16 de noviembre, sobre reutilización de la información del sector público, tiene por objeto la apertura de datos de estas instituciones para que se cree y genere valor.

Ese es uno de los objetivos de los datos abiertos, la creación de valor mediante la liberación y publicación de los elementos que gestionan los archivos, bibliotecas y museos. Pero no solo se puede trabajar en ofrecer las descripciones de los fondos que les son propios, sean recursos bibliográficos en las bibliotecas; museísticos, en los museos; o documentales, en los archivos, sino también la de la gran variedad de objetos de todo tipo que suelen disponer entre sus fondos, con sus datos descriptivos asociados.

Ofrecer la descripción y datos de estos recursos debe ir acompañado de abrir la propia institución, aportando cualquier tipo de información correctamente estructurada, bajo formatos abiertos a través de opendata. Por ejemplo, la agenda de eventos, estadísticas, presupuesto, perfiles profesionales, cargos, novedades, últimas adquisiciones, donaciones, etc.

Los datos abiertos dan a conocer y posicionan a los archivos, bibliotecas y museos aportando su información para que pueda ser usada, reutilizada y difundida. $Y$ remarcar que abrir datos y publicarlos en formatos abiertos es totalmente compatible con los posibles derechos de propiedad intelectual y con el respeto más estricto a la protección de datos personales.

Por citar un ejemplo, DARA: Documentos y archivos de Aragón está en Aragón Open Data, y desde el portal de datos abiertos se ofrecen esas mismas descripciones existentes en el portal de archivos aragoneses, pero a través de formatos abiertos. $Y$ si en el portal DARA se cumple la normativa (protección de datos persona-
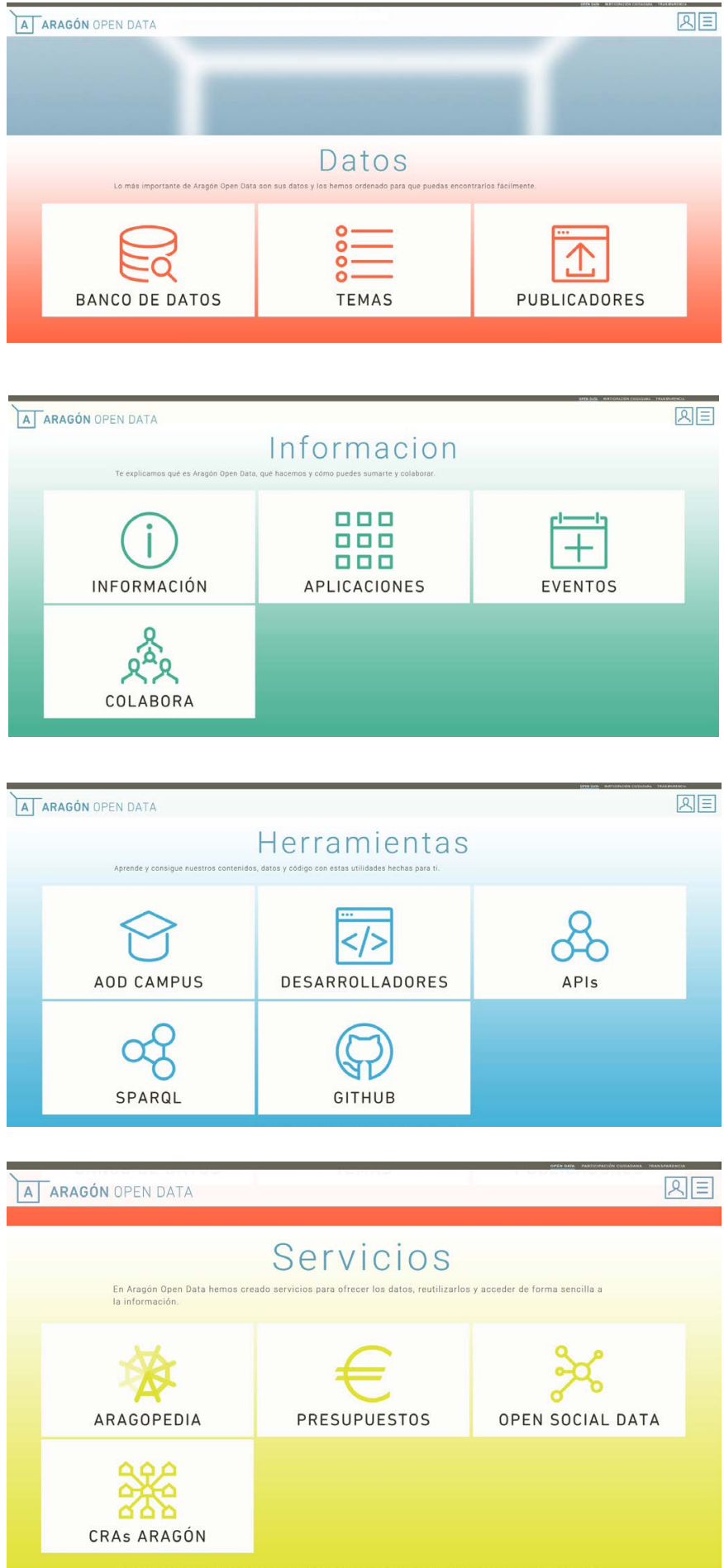

Aragón Open Data (http://opendata.aragon.es) 

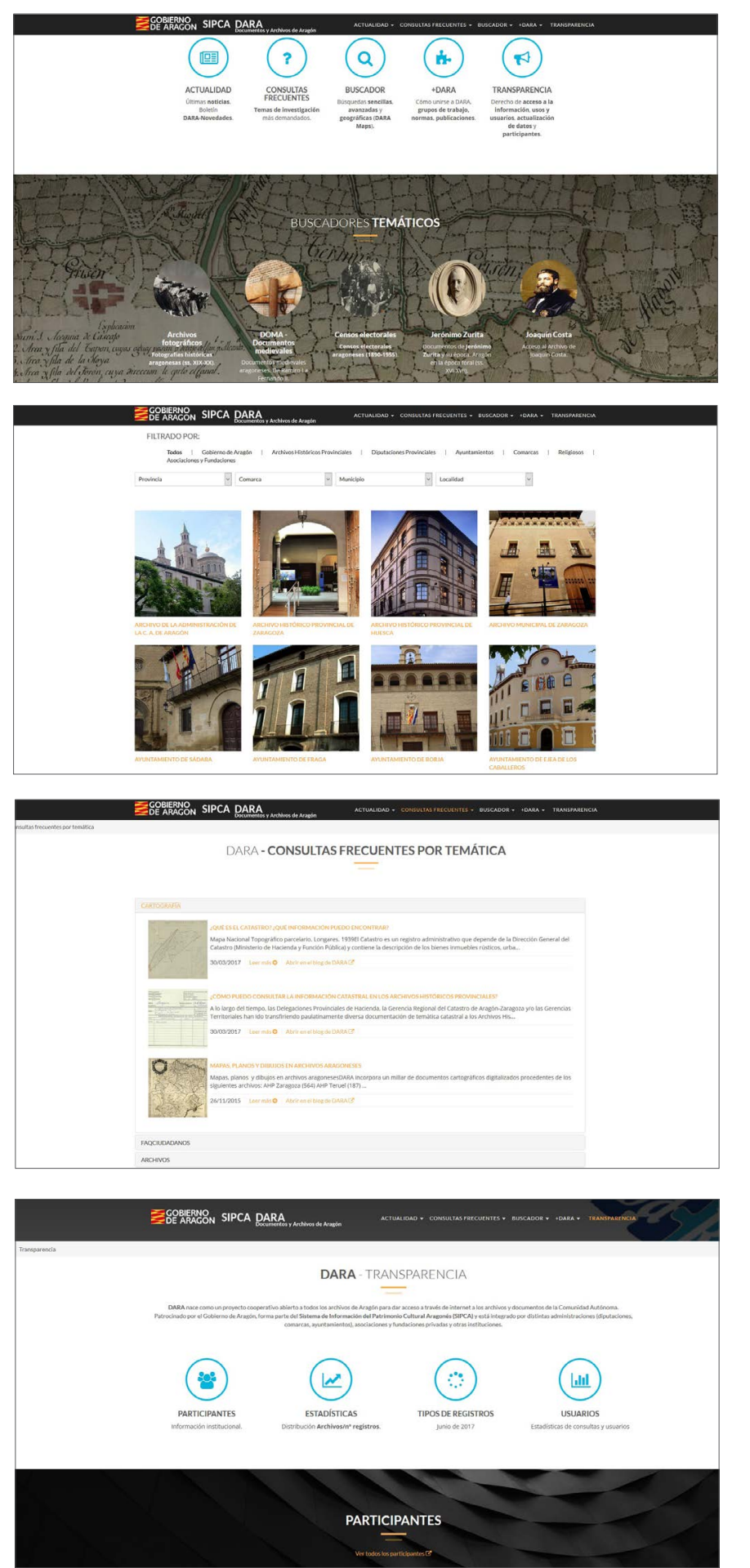

Documentos y archivos de Aragón (http://www.sipca.es/dara/\#) les, ley de secretos oficiales, acceso...) en Aragón Open Data, también. Y además es el portal de datos abiertos el que sustenta las obligaciones de estas instituciones en materia de reutilización de la información en el marco de la mencionada Ley 18/2015.

Los datos de archivos, bibliotecas y museos son una singular e importante fuente de conocimiento que pueden aportar y enriquecer a otros contenidos. Gracias a la apertura se fomenta el desarrollo de nuevos servicios que se sirven o apoyan en estos datos. Por ejemplo mapas enriquecidos, aplicaciones móviles, aplicaciones científicas o información turística son algunas de las líneas en las que se está trabajando. Las posibilidades pueden ser muchas y dependerán en buena medida del uso e interés que quieran hacer los usuarios y desarrolladores de ellos.

Y por tanto, este último párrafo invita a pensar que abrir datos en archivos, bibliotecas y museos no es ningún fin en sí mismo; es un medio que va a posibilitar nuevos recursos y servicios gracias a la reutilización de estos. Ese es el verdadero valor de los datos abiertos. 